\title{
Changing paradigms in breast cancer treatment
}

\author{
Shan $\mathrm{Ali}^{1 *} \oplus$, Dagmara Buczek ${ }^{2 *} \oplus$, Jacek Jassem² $₫$
}

*These authors contributed equally to the manuscript

${ }^{1}$ Medical University of Gdańsk, Poland

${ }^{2}$ Department of Oncology and Radiotherapy, Medical University of Gdańsk, Poland

\begin{abstract}
In only the past century, the landscape of breast cancer treatment has completely changed. The Halstedian hypothesis of the "contiguous spread" of breast cancer has been replaced by a consideration of its systemic nature. Today, patients with early-stage breast cancer are managed with breast-conserving therapy, which is as effective as mastectomy. Sentinel lymph node biopsy has largely replaced axillary lymph node dissection. Post-operative radiotherapy, chemotherapy and endocrine therapy have increased survival. Pre-operative cytotoxic therapy allows for less extensive surgery and for a curative resection even in more advanced stages. Rapid progress in molecular oncology revealed a large heterogeneity of breast cancer, resulting in a more personalized approach. Targeted therapies directed against epidermal growth factor receptor type 2 (HER2) have improved survival in HER2-positive breast cancer, which was once a poor-prognosis entity. Multi-gene prognostic signatures better predict prognosis and allow many patients to avoid chemotherapy. Personalized treatment has resulted in decreased toxicity and an improved quality of life. Within the past decades, breast cancer has become a good-prognosis malignancy with a five-year survival in the range of $80-85 \%$. Future development of personalized medicine may further refine treatment based on the tumor's molecular features.
\end{abstract}

Keywords: breast cancer $\cdot$ sentinel node biopsy $\cdot$ breast-conserving surgery $\cdot$ targeted therapy $\cdot$ molecular profiles

\section{Citation}

Ali S, Buczek D, Jassem J. Changing paradigms in breast cancer treatment. Eur J Transl Clin Med. 2020;3(2):53-63. DOI: $10.31373 /$ ejtcm/130486

Corresponding author:

Jacek Jassem, Department of Oncology and Radiotherapy, Medical University of Gdańsk, Gdańsk, Poland

e-mail: jjassem@gumed.edu.pl

No external funds.

Available online: www.ejtcm.gumed.edu.pl

$\underset{\substack{\text { TRANSPARENT } \\ \text { PROCESS }}}{2}$

Copyright ${ }^{\circledR}$ Medical University of Gdańsk

This is Open Access article distributed under the terms of the Creative Commons Attribution-ShareAlike 4.0 International. 


\section{Introduction}

Breast cancer is the most common female malignancy worldwide and is the leading cause of cancer death, accounting for $24.2 \%$ of the total cancer cases and $15.5 \%$ of cancer deaths in women [1]. Once a virtually incurable entity, it is now considered a good-prognosis malignancy with an $80-85 \%$ five-year survival. This spectacular achievement is a result of a better understanding of this tumor's biology, early detection and diagnosis, and progress in treatment. Over the past century, the management of breast cancer has undergone fundamental evolution which not only has resulted in better clinical outcomes, but has also allowed for satisfactory patient survival. This article will outline important milestones and the changing paradigms of breast cancer treatment.

From radical mastectomy to breast conserving therapy

On May 8, 1907, William S. Halsted, a Johns Hopkins University surgeon, declared at the American Surgical Association conference that "breast cancer follows a predictable pattern of spread from one to the next echelon" and that "(a)n en bloc removal of all echelons could thus achieve a cure." With this assumption, he proposed a drastic and disfiguring procedure in which the entire breast, pectoral muscles and axillary lymph nodes were removed. This therapy initiated the so-called "Halstedian era" of breast cancer treatment and radical mastectomy became the standard management for more than half of the $20^{\text {th }}$ century [2]. Although radical mastectomy was widely adopted, surgeons were searching for new solutions. As early as the 1930s, David Patey from London modified Halsted's operation by saving the pectoralis major muscle. This type of surgery was less traumatic and reduced the risk of postoperative complications, e.g. post-mastectomy pain syndrome, lymphedema and a reduced range of motion in the upper limb. To the contrary, there were also attempts to extend breast cancer surgery with a so-called supraradical mastectomy, including the chest wall, internal mammary lymph nodes or even the supraclavicular and mediastinal nodes. These procedures, however, were associated with significant morbidity and no clinical benefit [2].

The major treatment paradigm shift began in the 1960s, when another American surgeon, Bernard Fisher, presented his theory of the systemic nature of breast cancer. As opposed to Halsted's theory of locoregional spread, he argued that women suffering from breast cancer die due to metastatic disease. Hence, surgery may be less extensive, and should be supplemented by systemic therapy to combat micrometastases and reduce the risk of tumor dissemination [3]. Fisher and his colleagues from the National Surgical Adjuvant Project for Breast and Bowel Cancers (NSABP) initiated an era of optimized surgical approaches and systemic adjunctive therapies that were based on randomized clinical trials (RCTs) rather than on empirical grounds.

In the 1970s, the researchers at the NSABP conducted a randomized three-arm trial comparing radical mastectomy to a total (also referred to as "simple") mastectomy (removal of the breast tissue, areola, nipple and skin without axillary dissection), the latter with or without regional irradiation [4]. Axillary dissection was performed only if the lymph nodes became subsequently positive. After 10 years, there was no significant survival difference between the two groups. Consequently, a modified radical mastectomy, sparing the pectoralis major muscle, became the new standard in the 1980s [2]. The next breakthrough in breast cancer surgery was the B-06 clinical trial initiated in the 1970s also by the NSABP [5]. This time, the reasearchers compared the efficacy of total mastectomy and breast conserving surgery (BCS), which included removal of the tumor with surrounding breast tissue. Overall survival (OS) was comparable in both approaches, however the disease-free survival (DFS) was highly improved among patients managed with BCS thanks to the post-operative radiotherapy. At the same time, Umberto Veronesi from the Istituto Tumori di Milano (Italy) published an RCT comparing radical mastectomy and quadrantectomy, another form of BCS [6]. His study supported the paradigm shift from a maximum tolerated surgery to a minimal effective surgery. These results led the National Institutes of Health (NIH; USA) to recommend BCS followed by whole breast radiotherapy as a new standard management in early-stage breast cancer in 1990. Later results of the NSABP and Italian studies confirmed the durable efficacy of breast-saving approaches and established their role in routine practice [7-8].

\section{Avoiding axillary lymphadenectomy}

Despite the shortcomings of the "predictable spread" theory of breast cancer, Halstead was not entirely wrong. Indeed, in more than $90 \%$ of cases the disease spreads in a predictable manner from level-I through level-II to level-III axillary lymph nodes. After almost a century, his theory resulted in the concept of the sentinel lymph node biopsy (SLNB). 
A sentinel lymph node (SLN) is defined as the initial lymph node to which cancer is most likely to spread from the primary tumor. Axillary lymph node dissection (ALND) has long been considered a routine part of breast cancer management, because clinical examination was unreliable for detection of axillary involvement. However, ALND is associated with several side effects including arm edema, numbness, pain and affected arm mobility. Hence, avoiding ALND may substantially improve a patient's quality of life. SLNB was first employed in the treatment of parotid tumors and melanoma [9-10], and breast cancer seemed to be another good model for this procedure. Indeed, SLNB in breast cancer was found to accurately predict the status of the entire axilla [11]. Armando Giuliano (USA) used blue dye, while Veronesi (Italy) used radiocolloid to identify SLN in breast cancer and both successfully demonstrated axillary nodal involvement [9-10] and the combination thereof was more reliable than either used alone [11-12]. A series of randomized studies confirmed a similar OS with SLNB and lymphadenectomy in breast cancer patients with clinically negative axillary lymph nodes [13-16]. In consequence, patients with a negative SLNB are currently managed without ALND. Further studies showed that even patients with 1-2 positive SLNs may forego ALND without compromising OS, provided surgery is followed by post-operative radiotherapy including the axilla [17-18]. ALND may also be avoided in node positive patients who achieve negative SLNB following pre-operative chemotherapy [19].

While Halstead was right on certain points, his theory did not consider breast cancer as a systemic disease. Understanding that breast cancer deaths are caused mainly by the tumor dissemination led to studies of adjuvant systemic therapies.

The first major study investigating adjuvant chemotherapy after surgery in breast cancer was published by Bernard Fisher et al in 1968 [20]. The authors concluded that single cytotoxic agent thio-tepa administered postoperatively in pre-menopausal patients decreases the risk of cancer recurrence death. In 1976, the Italian oncologist Gianni Bonadonna presented a spectacular benefit of postoperative multi-drug regimen including cyclophosphamide, methotrexate and fluorouracil (CMF), which later became the standard adjuvant treatment in breast cancer [21]. These findings were supported by other large trials performed by the NSABP and other research teams [22-25]. In the 1980s, chemothe- rapy improved from CMF to regimens including anthracyclines (doxorubicin, epirubicin), followed by the even more effective taxane combinations (paclitaxel, docetaxel) [26-30] in the 1990s [29-33]. With increasing evidence supporting survival benefit of adjuvant chemotherapy, in 2001 the NIH recommended its use in the majority of women with localized breast cancer, regardless of lymph node, menopausal or hormone receptor status [31].

More recently, there is an increasing trend of administering chemotherapy in the pre-operative period, rather than post-operative [32]. This approach aims at eradicating potential occult micrometastases present already at diagnosis and reducing tumor mass to enable curative mastectomy or even BCS in selected cases. Pre-operative chemotherapy results in remission of nodal metastases, thus allowing for less extensive axillary surgery and for tailoring postoperative radiotherapy [36]. Additionally, administration of chemotherapy prior to surgery provides vital information on tumor behavior in vivo, allows chemosensitivity assessment and offers pathological complete response $(p C R)$ as a surrogate outcome marker of clinical benefit $[3,33]$. Currently, pre-operative chemotherapy is routinely used in locally advanced and large primary breast cancers and provides apparent benefit in more aggressive phenotypes, such as triple negative and HER2-positive breast cancer. There was a word of warning regarding this strategy, however. Namely, a meta-analysis by the Early Breast Cancer Trialists' Collaborative Group (EBCTCG) showed no difference between pre- and post-operative chemotherapy in terms of all-cause mortality, but there were more local recurrences ( $21.4 \%$ vs. $15.9 \%)$ with the former, likely due to more BCSs in this setting [34]. These data indicate the need to mitigate the risk of local failure in patients managed with induction chemotherapy.

\section{Targeted therapies}

The starting point of targeted treatment of breast cancer was anti-estrogen receptor (ER) therapy. In 1977, the US Food and Drug Administration (FDA) approved tamoxifen as the first clinically viable selective ER modulator for metastatic breast cancer. Anti-estrogen therapy was a noteworthy breakthrough, because it had a greater global impact than any other therapeutic intervention in oncology.

Several large studies demonstrated that tamoxifen in ER-positive breast cancer significantly improved the post-operative outcome. Another EBCTCG meta-analysis demonstrated a $9.2 \%$ improvement of 15 -year overall survival (OS) after a 5-year therapy of tamoxifen in ER-positive or ER-unknown breast cancer [35]. Tamoxifen 
began to gain a proven position in cancer prevention, treatment of ductal carcinoma in situ (DCIS) and in early and advanced invasive breast cancer. Subsequently, a series of large clinical studies demonstrated higher efficacy of aromatase inhibitors (anastrozole, letrozole and exemestane) in hormone-sensitive breast cancers [36]. Extending hormone therapy beyond the standard five years allowed for an increase of DFS in patients with a higher risk of relapse [37-38]. Another approach for increasing DFS was combining tamoxifen or an aromatase inhibitor with a pharmacologic ovarian suppressor in high risk premenopausal women [39]. A recent development in the treatment of ER-positive advanced breast cancer was combining adding cyclin-dependent kinase 4 and 6 inhibitors (palbociclib, ribociclib and abemaciclib) [40-42]. These compounds act at the G1-to-S cell cycle checkpoint, leading to cell cycle arrest [43]. Advances in molecular biology, identified PIK3CA/mTOR signaling as a mechanism of resistance in ER-positive tumors, and the PI3K inhibitor alpelisib has shown promising activity [44].

Another milestone in the development of patient-tailored therapy was the discovery of the HER2-neu protooncogene in the 1980s [45-46]. Amplification or overexpression of this gene played a key role in the development and progression of an aggressive form of breast cancer called HER2-positive cancer. This discovery initiated the era of anti-HER2 therapy. The first anti-HER2 drug approved by the FDA was trastuzumab (Herceptin), a humanized monoclonal antibody. Clinical benefit of trastuzumab added to chemotherapy in HER2-positive advanced breast cancer was first demonstrated in 2001 by Slamon et al [47]. Subsequently, a series of large randomized studies showed a spectacular effi- cacy of this compound in the adjuvant setting in patients with an overexpression or amplification of HER2 [48].

Within the next 20 years the array of anti-HER2 therapies has expanded to include small molecule tyrosine kinase inhibitors (lapatinib, neratinib, tucatinib), second-generation monoclonal antibody pertuzumab and conjugates of trastuzumab with cytotoxic agents (trastuzumab emtansine, trastuzumab deruxtecan).

Breast cancer as a heterogeneous disease

Currently it is understood that breast cancer is a clinically and pathologically heterogeneous group of pathologic entities with different biologic and clinical behaviors. Immunohistochemistry techniques allow for the distinction of hormone receptor (ER or progesterone receptor, PR)-positive, triple-negative and HER2-positive breast cancers. In the 21st century genetic profiling led to the classification of breast cancer into five intrinsic molecular types: luminal A, luminal B, HER2-enriched, basal-like and normal-like breast cancer [49].

These subtypes are characterized by different clinical behavior and their distinction provides relevant information beyond pathology-based classifications [50]. In daily clinical practice, intrinsic molecular subtypes are replaced by their surrogates based on the immunohistochemistry expression of hormone receptors, overexpression of HER2, and a Ki67 score which is a cellular marker of proliferation. This classification is routinely used in clinical practice to assess prognosis and to select adjuvant systemic therapies in breast cancer patients (Table 1).

Table 1. Principles of perioperative systemic therapy for breast cancer

\begin{tabular}{|c|c|c|c|c|c|}
\hline \multicolumn{2}{|c|}{ Phenotype } & Subtype & Endocrine therapy & Anti-HER2 therapy & Chemotherapy \\
\hline $\begin{array}{l}\text { Hormone } \\
\text { receptors }\end{array}$ & HER & & & & \\
\hline+ & 一 & $\begin{array}{c}\text { Luminal A } \\
\text { or luminal } \\
\text { B HER2-negative }\end{array}$ & Yes & No & Yes (if high risk) \\
\hline+ & + & $\begin{array}{l}\text { Luminal B } \\
\text { HER2-positive }\end{array}$ & Yes & Yes & Yes \\
\hline 一 & 一 & Triple negative & No & No & Yes \\
\hline- & + & HER2-positive & No & Yes & Yes \\
\hline
\end{tabular}


Can molecular signatures predict prognosis?

The use of perioperative chemotherapy resulted in declining breast cancer mortality rates on a global scale. Moreover, the effectiveness of chemotherapy allowed for more conservative breast and axillary surgery. There was however a general conviction that adjuvant chemotherapy may be avoided in a proportion of patients, however there were no reliable instruments to predict individual risk of relapse.

Better understanding of molecular biology led to the development of several multigene tests which better predict prognosis of breast cancer and select patients to chemotherapy. Some examples of these assays include Oncotype DX ${ }^{\circledR}$ (Exact Sciences, United States), MammaPrint ${ }^{\circledR}$ (Agendia, Netherlands), Endopredict (Sividon Diagnostics $\mathrm{GmbH}$, Koln, Germany), PAM50/Prosigna (Nanostring Technologies, USA) and Breast Cancer Index SM (bioTheranostics, USA) [51]. Two of these assays have been subjected to large randomized trials: MINDACT and TAILORx. The first trial, using MammaPrint test (a 70-gene signature), demonstrated that chemotherapy may be avoided in both low genomic (according to the signature) and low clinical (small tumor, N0, low grading) risk groups [52]. Whereas the second trial (TAILORx) using Oncotype DX (a 21-gene signature) showed no benefit from adjuvant chemotherapy for node-negative ER-positive and HER2-negative breast cancer patients with an intermediate recurrence score [53]. Importantly, this subset constituted around $70 \%$ of patients in the study group and with a standard clinical criteria most of them would be exposed to unnecessary chemotherapy. Whereas first-generation signatures (MammaPrint, OncotypeDX, Genomic Grade Index) reliably predict a five year prognosis, newer assays (Breast Cancer Index, EndoPredict, PAM50) are also prognostic for late recurrence, enabling patient survival to be prolonged by adjuvant endocrine therapy [54].

Unfortunately, multigene signatures have several limitations. First, their prognostic utility is restricted to ER-positive, T1-2 breast cancers with 0 to 3 positive lymph nodes. Since these test use ER-related and proliferation genes, they assign all ER-negative tumors to a high-risk category [58]. There is also a $20-30 \%$ discordance between particular multigene signatures in predicting the risk for individual patients [54, 56-58]. Finally, molecular assays do not indicate the most effective chemotherapy regimen and do not allow for the development of new strategies in high risk groups. Despite these shortcomings, prognostic signatures provide useful information and have been adopted by the American Society of Clinical Oncology (ASCO),
National Comprehensive Cancer Network (NCCN) and the St. Gallen guidelines as a useful tool in helping physicians to make decisions about adjuvant treatment in ER-positive breast cancer patients [54, 59-62].

\section{Improving the breast cancer survivors'} quality of life

Significant progress in breast cancer treatment has resulted in increasing the number of survivors facing treatment-related side effects. Chemotherapy used for breast cancer often induces early menopause, may be cardiotoxic, ototoxic, neurotoxic and even carcinogenic. Endocrine treatment increases the risk of endometrial cancer, thromboembolic events, cataracts, osteoporosis, bone fractures, metabolic disorders (aromatase inhibitors) and hot flashes (tamoxifen). The anti-HER2 antibody (trastuzumab) is cardiotoxic and causes infusion-related reactions. Surgical treatment, particularly mastectomy, is disfiguring and affects both physical and psychological health. Finally, radiotherapy of left-sided tumors may induce late cardiotoxicity. Apart from the increasing treatment efficacy, an important aim of current approaches is therefore maintaining a good quality of life during and after treatment. Examples of these developments include breast reconstruction, effective antiemetic treatment, caring for bone health, and prevention of alopecia and neuropathy. Cancer support groups are proven to be effective for patients, spouses and other family members in reducing the emotional burden of a cancer diagnosis and treatment [63]. Another valuable aspect of supportive care in breast cancer patients is reducing the risk of treatment-related infertility [64].

Physical and mental rehabilitation after cancer treatment is not only vital for patients and their families but, given a high incidence of this malignancy, also has an important economic value. The prevalence of the return to work rate (RTW) is in the range of $43 \%$ to $93 \%$ within one year of diagnosis [65]. As a large majority of women with breast cancer are still in their working age, a low RTW may put considerable burden on a national economy [66].

\section{Current challenges and outlook} for the future

Fundamental changes in breast cancer management, as well as the implementation of large-scale mammography screening programs resulted in remarkable progress in therapeutic outcomes. For example, 
between 1975 and 2002, the 10-year survival in the USA increased from $65 \%$ to $83 \%$ [67]. In consequence, the mortality from breast cancer in the USA decreased by $34 \%$ from 1975 to 2010, despite an incidence increase by $30 \%$ [67]. However, several major challenges remain for the current and next generation of physicians and scientists [68]. There are still no effective primary prevention measures. Tamoxifen, raloxifene and aromatase inhibitors (exemestane, anastrozole) have proved to decrease breast cancer risk [69-72]. However, they prevent only ER-positive breast cancers, do not provide survival benefit and carry considerable toxicity with long-term administration. Lifestyle changes to prevent breast cancer are not feasible for many women and their impact on survival can be modest.

Mammography has a proven role in screening for breast cancer, but it may also result in overdiagnosis and overtreatment of screened populations [73]. Therefore, there is a need for new tools to customize this method considering its benefits and perceived harms.

Systemic therapies sometimes fail to target micrometastases in the adjuvant setting and resistance to these drugs is a problem. An excellent diagnostic tool is a "liquid biopsy" exploiting circulating tumor cells or circulating tumor DNA or microRNA from a patient's blood. It can address monitoring of minimal residual disease after treatment, or even inform the selection of the most effective therapies [74-76].

Targeted biologic therapy has significantly transformed oncology, however triple-negative breast cancer seems to lack any target and there has been little progress in this worst prognosis entity [50]. Anti-HER2 therapies have upgraded the outcomes of HER2-positive breast cancer to the level of less aggressive subtypes, but the standard monoclonal antibody treatment does not combat occult brain disease which is particularly common in this subset. Recently, this shortcoming has partly been overcome though, with small molecule HER2 tyrosine kinase inhibitors [77]. Breast cancer treatment is moving towards a more individualized approach. Figure 1 outlines five major factors influencing the selection of systemic therapies for breast cancer patients. Better prediction of tumor response has led to the evolution of adjuvant systemic therapies from being based on the level-of-risk to considering first the expected response to treatment (Figure 2). Future endeavors hope to further develop tailored treatment based on patient pharmacogenomics and tumor molecular features. One approach that holds promise in the field of personalized therapy are immune and microenvironment gene signatures which, as opposed to current multigene assays, can predict prognosis also in ER-negative tumors [78-79].

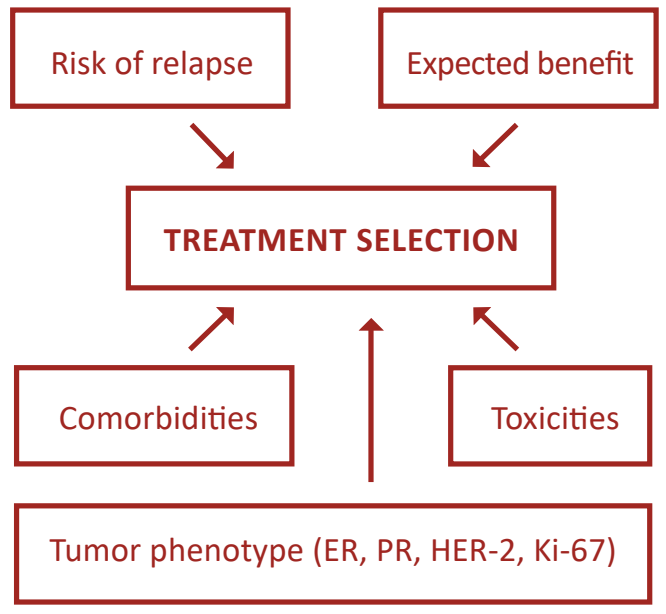

Figure 1. Major factors influencing the selection of systemic therapies for primary breast cancer

Abbreviations: ER - estrogen receptor; PR - progesterone receptor; HER-2 - human epidermal growth factor receptor 2

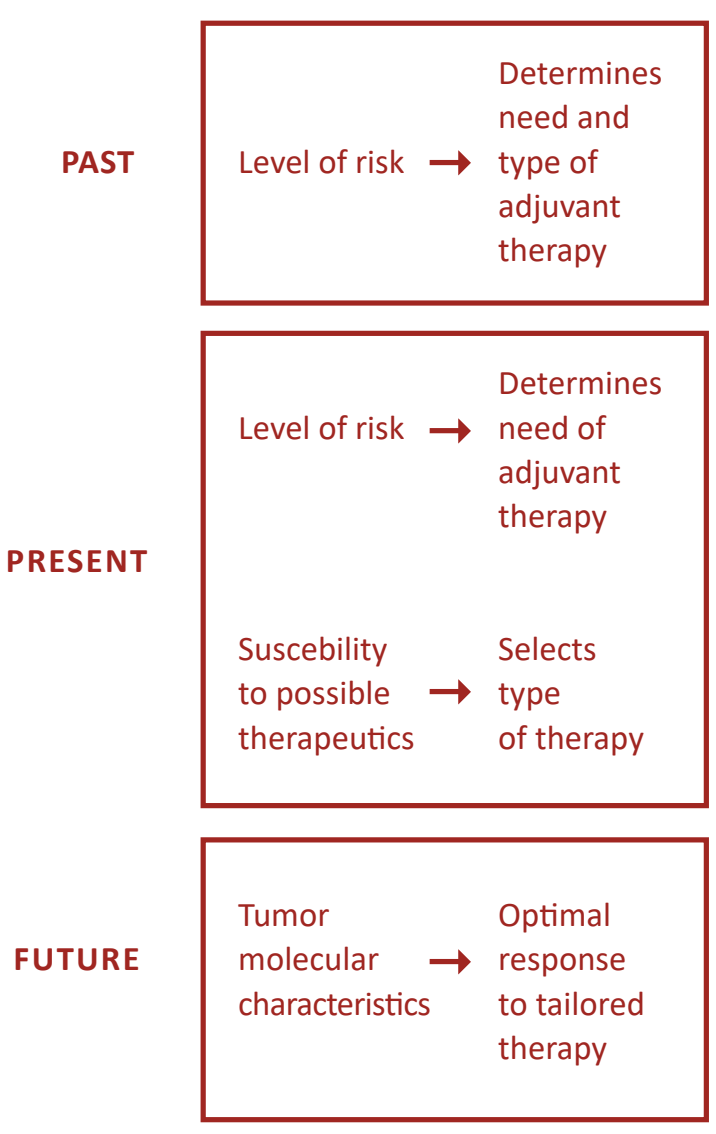

Figure 2. Conceptual evolution in selecting adjuvant systemic therapies 


\section{Conclusions}

The paradigms in the treatment of breast cancer have changed considerably over the past century. Today, a more conservative surgery improves a breast cancer patients' quality of life without compromising survival and the axillary lymph nodes may be saved in a majority of patients. Adjuvant systemic therapies have reduced mortality and transformed breast cancer from a terminal illness into a curable one. Molecular biology has elucidated disease mechanisms and led to the development of truly personalized medicine. Despite these advances, there are still several challenges. Future research should be focused on developing valuable preventive strategies, better screening tests and images, better predictive gene assays and more effective therapies for the worst outcome subtypes.

Declarations of interest: Jacek Jassem MD PhD: Roche, Pfizer (travel support), Astra Zeneca, BMS, Pfizer, MSD, Takeda (consulting/advisory relationship).

Funding: This research did not receive any specific grant from agencies in the public, commercial, or not-for-profit sectors.

Ethical permission: Ethical approval was not necessary for the preparation of this article.

\section{References}

1. Bray F, Ferlay J, Soerjomataram I, Siegel RL, Torre LA, Jemal A. Global cancer statistics 2018: GLOBOCAN estimates of incidence and mortality worldwide for 36 cancers in 185 countries. CA Cancer J Clin [Internet]. 2018 Nov;68(6):394-424. Available from: http://doi.wiley.com/10.3322/caac.21492

2. Cotlar AM, Dubose JJ, Rose DM. History of surgery for breast cancer: radical to the sublime. Curr Surg [Internet]. 2003 May;60(3):329-37. Available from: https://linkinghub.elsevier.com/retrieve/pii/s0149794402007778

3. Chintamani. The Paradigm Shifts in the Management of Breast Cancer - Have We Finally Arrived? Indian J Surg [Internet]. 2013 Dec 28;75(6):419-23. Available from: http://link.springer.com/10.1007/s12262-013-1022-1

4. Fisher B, Redmond C, Fisher ER, Bauer M, Wolmark N, Wickerham DL, et al. Ten-Year Results of a Randomized Clinical Trial Comparing Radical Mastectomy and Total Mastectomy with or without Radiation. N Engl J Med [Internet]. 1985 Mar 14;312(11):674-81. Available from: http://www.nejm.org/doi/abs/10.1056/NEJM198503143121102

5. Fisher B, Bauer M, Margolese R, Poisson R, Pilch Y, Redmond C, et al. Five-Year Results of a Randomized Clinical Trial Comparing Total Mastectomy and Segmental Mastectomy with or without Radiation in the Treatment of Breast Cancer. N Engl J Med [Internet]. 1985 Mar 14;312(11):665-73. Available from: http://www.nejm.org/doi/abs/10.1056/ NEJM198503143121101

6. Veronesi U, Saccozzi R, Del Vecchio M, Banfi A, Clemente C, De Lena M, et al. Comparing Radical Mastectomy with Quadrantectomy, Axillary Dissection, and Radiotherapy in Patients with Small Cancers of the Breast. N Engl J Med [Internet]. 1981 Jul 2;305(1):6-11. Available from: http://www.nejm.org/doi/abs/10.1056/NEJM198107023050102

7. Veronesi U, Cascinelli N, Mariani L, Greco M, Saccozzi R, Luini A, et al. Twenty-Year Follow-up of a Randomized Study Comparing Breast-Conserving Surgery with Radical Mastectomy for Early Breast Cancer. N Engl J Med [Internet]. 2002 Oct 17;347(16):1227-32. Available from: http://www.nejm.org/doi/abs/10.1056/NEJMoa020989

8. Fisher B, Anderson S, Bryant J, Margolese RG, Deutsch M, Fisher ER, et al. Twenty-Year Follow-up of a Randomized Trial Comparing Total Mastectomy, Lumpectomy, and Lumpectomy plus Irradiation for the Treatment of Invasive Breast Cancer. N Engl J Med [Internet]. 2002 Oct 17;347(16):1233-41. Available from: http://www.nejm.org/doi/abs/10.1056/NEJMoa022152

9. Veronesi U, Paganelli G, Galimberti V, Viale G, Zurrida S, Bedoni M, et al. Sentinel-node biopsy to avoid axillary dissection in breast cancer with clinically negative lymph-nodes. Lancet [Internet]. 1997 Jun;349(9069):1864-7. Available from: https://linkinghub.elsevier.com/retrieve/pii/S0140673697010040

10. Giuliano AE. Guest editorial: Sentinel lymphadenectomy in primary breast carcinoma: An alternative to routine axillary dissection. J Surg Oncol [Internet]. 1996 Jun;62(2):75-7. Available from: https://onlinelibrary.wiley.com/doi/10.1002/ (SICI)1096-9098(199606)62:2\%3C75::AID-JSO1\%3E3.0.CO;2-N

11. Linehan DC, Hill ADK, Akhurst T, Yeung H, Yeh SDJ, Tran KN, et al. Intradermal Radiocolloid and Intraparenchymal Blue Dye Injection Optimize Sentinel Node Identification in Breast Cancer Patients. Ann Surg Oncol [Internet]. 1999 Jul;6(5):450-4. Available from: http://link.springer.com/10.1007/s10434-999-0450-4

12. Tsugawa K, Noguchi M, Miwa K, Bando E, Yokoyama K, Nakajima K, et al. Dye- and gamma probe-guided sentinel lymph node biopsy in breast cancer patients: using patent blue dye and technetium-99m-labeled human serum albumin. Breast Cancer [Internet]. 2000 Jan;7(1):87-94. Available from: http://link.springer.com/10.1007/BF02967195 
13. Krag DN, Anderson SJ, Julian TB, Brown AM, Harlow SP, Costantino JP, et al. Sentinel-lymph-node resection compared with conventional axillary-lymph-node dissection in clinically node-negative patients with breast cancer: overall survival findings from the NSABP B-32 randomised phase 3 trial. Lancet Oncol [Internet]. 2010 Oct;11(10):927-33. Available from: https://linkinghub.elsevier.com/retrieve/pii/S1470204510702072

14. Canavese G, Catturich A, Vecchio C, Tomei D, Gipponi M, Villa G, et al. Sentinel node biopsy compared with complete axillary dissection for staging early breast cancer with clinically negative lymph nodes: results of randomized trial. Ann Oncol [Internet]. 2009 Jun;20(6):1001-7. Available from: https://linkinghub.elsevier.com/retrieve/pii/S0923753419410624

15. Veronesi U, Viale G, Paganelli G, Zurrida S, Luini A, Galimberti V, et al. Sentinel Lymph Node Biopsy in Breast Cancer. Ann Surg [Internet]. 2010 Apr;251(4):595-600. Available from: http://journals.Iww.com/00000658-201004000-00003

16. Galimberti V, Cole BF, Zurrida S, Viale G, Luini A, Veronesi $P$, et al. Axillary dissection versus no axillary dissection in patients with sentinel-node micrometastases (IBCSG 23-01): a phase 3 randomised controlled trial. Lancet Oncol [Internet]. 2013 Apr;14(4):297-305. Available from: https://linkinghub.elsevier.com/retrieve/pii/S1470204513700354

17. Giuliano AE, McCall L, Beitsch P, Whitworth PW, Blumencranz P, Leitch AM, et al. Locoregional Recurrence After Sentinel Lymph Node Dissection With or Without Axillary Dissection in Patients With Sentinel Lymph Node Metastases. Trans. Meet Am Surg Assoc [Internet]. 2010;128(3):12-21. Available from: http://journals.Iww.com/00153307201001280-00002

18. Donker M, van Tienhoven G, Straver ME, Meijnen P, van de Velde CJH, Mansel RE, et al. Radiotherapy or surgery of the axilla after a positive sentinel node in breast cancer (EORTC 10981-22023 AMAROS): a randomised, multicentre, open-label, phase 3 non-inferiority trial. Lancet Oncol [Internet]. 2014 Nov;15(12):1303-10. Available from: https://linkinghub. elsevier.com/retrieve/pii/S1470204514704607

19. Balic M, Thomssen C, Würstlein R, Gnant M, Harbeck N. St. Gallen/Vienna 2019: A Brief Summary of the Consensus Discussion on the Optimal Primary Breast Cancer Treatment. Breast Care [Internet]. 2019;14(2):103-10. Available from: https://www.karger.com/Article/FullText/499931

20. Fisher B, Ravdin RG, Ausman RK, Slack NH, Moore GE, Noer RJ. Surgical Adjuvant Chemotherapy in Cancer of the Breast. Ann Surg [Internet]. 1968 Sep;168(3):337-56. Available from: http://journals.Iww.com/00000658-196809000-00004

21. Bonadonna G, Brusamolino E, Valagussa P, Rossi A, Brugnatelli L, Brambilla C, et al. Combination Chemotherapy as an Adjuvant Treatment in Operable Breast Cancer. N Engl J Med [Internet]. 1976 Feb 19;294(8):405-10. Available from: http://www.nejm.org/doi/abs/10.1056/NEJM197602192940801

22. Fisher B, Glass A, Redmond C, Fisher ER, Barton B, Such E, et al. L-phenylalanine mustard (L-PAM) in the management of primary breast cancer:An update of earlier findings and a comparison with those utilizing L-PAM plus 5-fluorouracil (5-FU). Cancer [Internet]. 1977 Jun;39(6):2883-903. Available from: https://onlinelibrary.wiley.com/doi/10.1002/10970142(197706)39:6\%3C2883::AID-CNCR2820390676\%3E3.0.CO;2-9

23. Henderson IC, Mouridsen H, Abe O, Abeloff M, Ahmann D, Andersen K, et al. Effects of Adjuvant Tamoxifen and of Cytotoxic Therapy on Mortality in Early Breast Cancer. N Engl J Med [Internet]. 1988 Dec 29;319(26):1681-92. Available from: http://www.nejm.org/doi/abs/10.1056/NEJM198812293192601

24. Fisher B, Redmond C, Wickerham DL, Bowman D, Schipper H, Wolmark N, et al. Doxorubicin-containing regimens for the treatment of stage II breast cancer: The National Surgical Adjuvant Breast and Bowel Project experience. J Clin Oncol [Internet]. 1989 May;7(5):572-82. Available from: http://ascopubs.org/doi/10.1200/JC0.1989.7.5.572

25. Mansour EG, Gray R, Shatila AH, Osborne CK, Tormey DC, Gilchrist KW, et al. Efficacy of Adjuvant Chemotherapy in HighRisk Node-Negative Breast Cancer. N Engl J Med [Internet]. 1989 Feb 23;320(8):485-90. Available from: http://www. nejm.org/doi/abs/10.1056/NEJM198902233200803

26. Fisher B, Brown AM, Dimitrov N V, Poisson R, Redmond C, Margolese RG, et al. Two months of doxorubicin-cyclophosphamide with and without interval reinduction therapy compared with 6 months of cyclophosphamide, methotrexate, and fluorouracil in positive-node breast cancer patients with tamoxifen-nonresponsive tumors: results from t. J Clin Oncol [Internet]. 1990 Sep;8(9):1483-96. Available from: http://ascopubs.org/doi/10.1200/JCO.1990.8.9.1483

27. Fisher B, Anderson S, Tan-Chiu E, Wolmark N, Wickerham DL, Fisher ER, et al. Tamoxifen and Chemotherapy for Axillary Node-Negative, Estrogen Receptor-Negative Breast Cancer: Findings From National Surgical Adjuvant Breast and Bowel Project B-23. J Clin Oncol [Internet]. 2001 Feb 15;19(4):931-42. Available from: http://ascopubs.org/doi/10.1200/ JCO.2001.19.4.931

28. Mamounas EP, Bryant J, Lembersky B, Fehrenbacher L, Sedlacek SM, Fisher B, et al. Paclitaxel After Doxorubicin Plus Cyclophosphamide As Adjuvant Chemotherapy for Node-Positive Breast Cancer: Results From NSABP B-28. J Clin Oncol [Internet]. 2005 Jun 1;23(16):3686-96. Available from: http://ascopubs.org/doi/10.1200/JC0.2005.10.517 
29. Henderson IC, Berry DA, Demetri GD, Cirrincione CT, Goldstein LJ, Martino S, et al. Improved Outcomes From Adding Sequential Paclitaxel but Not From Escalating Doxorubicin Dose in an Adjuvant Chemotherapy Regimen for Patients With Node-Positive Primary Breast Cancer. J Clin Oncol [Internet]. 2003 Mar 15;21(6):976-83. Available from: http://ascopubs. org/doi/10.1200/JCO.2003.02.063

30. Albain K, Anderson S, Arriagada R, Barlow W, Bergh J, Bliss J, et al. Comparisons between different polychemotherapy regimens for early breast cancer: meta-analyses of long-term outcome among 100000 women in 123 randomised trials. Lancet [Internet]. 2012 Feb;379(9814):432-44. Available from: https://linkinghub.elsevier.com/retrieve/pii/ $\underline{\text { S0140673611616255 }}$

31. Bowersox JA. National Institutes of Health Consensus Development Conference Statement: Adjuvant Therapy for Breast Cancer, November 1-3, 2000. JNCI J Natl Cancer Inst [Internet]. 2001 Jul 4;93(13):979-89. Available from: https://academic.oup.com/inci/article-lookup/doi/10.1093/inci/93.13.979

32. Wolmark N, Wang J, Mamounas E, Bryant J, Fisher B. Preoperative Chemotherapy in Patients With Operable Breast Cancer: Nine-Year Results From National Surgical Adjuvant Breast and Bowel Project B-18. JNCI Monogr [Internet]. 2001 Dec 1;2001(30):96-102. Available from: https://academic.oup.com/incimono/article-lookup/doi/10.1093/oxfordjournals. incimonographs.a003469

33. Rastogi P, Anderson SJ, Bear HD, Geyer CE, Kahlenberg MS, Robidoux A, et al. Preoperative Chemotherapy: Updates of National Surgical Adjuvant Breast and Bowel Project Protocols B-18 and B-27. J Clin Oncol [Internet]. 2008 Feb 10;26(5):778-85. Available from: http://ascopubs.org/doi/10.1200/JCO.2007.15.0235

34. Asselain B, Barlow W, Bartlett J, Bergh J, Bergsten-Nordström E, Bliss J, et al. Long-term outcomes for neoadjuvant versus adjuvant chemotherapy in early breast cancer: meta-analysis of individual patient data from ten randomised trials. Lancet Oncol [Internet]. 2018 Jan;19(1):27-39. Available from: https://linkinghub.elsevier.com/retrieve/pii/ $\underline{\text { S1470204517307775 }}$

35. Abe O, Abe R, Enomoto K, Kikuchi K, Koyama H, Masuda H, et al. Effects of chemotherapy and hormonal therapy for early breast cancer on recurrence and 15-year survival: an overview of the randomised trials. Lancet [Internet]. 2005 May;365(9472):1687-717. Available from: https://linkinghub.elsevier.com/retrieve/pii/S0140673605665440

36. Dowsett M, Cuzick J, Ingle J, Coates A, Forbes J, Bliss J, et al. Meta-Analysis of Breast Cancer Outcomes in Adjuvant Trials of Aromatase Inhibitors Versus Tamoxifen. J Clin Oncol [Internet]. 2010 Jan 20;28(3):509-18. Available from: http:// ascopubs.org/doi/10.1200/JCO.2009.23.1274

37. Davies C, Pan H, Godwin J, Gray R, Arriagada R, Raina V, et al. Long-term effects of continuing adjuvant tamoxifen to 10 years versus stopping at 5 years after diagnosis of oestrogen receptor-positive breast cancer: ATLAS, a randomised trial. Lancet [Internet]. 2013 Mar;381(9869):805-16. Available from: https://linkinghub.elsevier.com/retrieve/pii/ $\underline{\text { S0140673612619631 }}$

38. Gray RG, Rea D, Handley K, Bowden SJ, Perry P, Earl HM, et al. aTTom: Long-term effects of continuing adjuvant tamoxifen to 10 years versus stopping at 5 years in 6,953 women with early breast cancer. J Clin Oncol [Internet]. 2013 Jun 20;31(18_suppl):5-5. Available from: http://ascopubs.org/doi/10.1200/ico.2013.31.18 suppl.5

39. Francis PA, Pagani O, Fleming GF, Walley BA, Colleoni M, Láng I, et al. Tailoring Adjuvant Endocrine Therapy for Premenopausal Breast Cancer. N Engl J Med [Internet]. 2018 Jul 12;379(2):122-37. Available from: http://www.nejm.org/ doi/10.1056/NEJMoa1803164

40. Finn RS, Martin M, Rugo HS, Jones S, Im S-A, Gelmon K, et al. Palbociclib and Letrozole in Advanced Breast Cancer. N Engl J Med [Internet]. 2016 Nov 17;375(20):1925-36. Available from: http://www.nejm.org/doi/10.1056/NEJMoa1607303

41. Hortobagyi GN, Stemmer SM, Burris HA, Yap Y-S, Sonke GS, Paluch-Shimon S, et al. Ribociclib as First-Line Therapy for HR-Positive, Advanced Breast Cancer. N Engl J Med [Internet]. 2016 Nov 3;375(18):1738-48. Available from: http://www. nejm.org/doi/10.1056/NEJMoa1609709

42. Johnston S, Martin M, Di Leo A, Im S-A, Awada A, Forrester T, et al. MONARCH 3 final PFS: a randomized study of abemaciclib as initial therapy for advanced breast cancer. npj Breast Cancer [Internet]. 2019 Dec 17;5(1):5. Available from: http://www.nature.com/articles/s41523-018-0097-z

43. Shah AN, Cristofanilli M. The Growing Role of CDK4/6 Inhibitors in Treating Hormone Receptor-Positive Advanced Breast Cancer. Curr Treat Options Oncol [Internet]. 2017 Jan 14;18(1):6. Available from: http://link.springer.com/10.1007/ $\underline{\text { s11864-017-0443-7 }}$

44. André F, Ciruelos E, Rubovszky G, Campone M, Loibl S, Rugo HS, et al. Alpelisib for PIK3CA -Mutated, Hormone ReceptorPositive Advanced Breast Cancer. N Engl J Med [Internet]. 2019 May 16;380(20):1929-40. Available from: http://www. nejm.org/doi/10.1056/NEJMoa1813904 
45. Slamon D, Clark G, Wong S, Levin W, Ullrich A, McGuire W. Human breast cancer: correlation of relapse and survival with amplification of the HER-2/neu oncogene. Science (80- ) [Internet]. 1987 Jan 9;235(4785):177-82. Available from: https://www.sciencemag.org/lookup/doi/10.1126/science.3798106

46. Slamon D, Godolphin W, Jones L, Holt J, Wong S, Keith D, et al. Studies of the HER-2/neu proto-oncogene in human breast and ovarian cancer. Science (80-) [Internet]. 1989 May 12;244(4905):707-12. Available from: https://www.sciencemag. org/lookup/doi/10.1126/science.2470152

47. Slamon DJ, Leyland-Jones B, Shak S, Fuchs H, Paton V, Bajamonde A, et al. Use of Chemotherapy plus a Monoclonal Antibody against HER2 for Metastatic Breast Cancer That Overexpresses HER2. N Engl J Med [Internet]. 2001 Mar 15;344(11):783-92. Available from: http://www.nejm.org/doi/abs/10.1056/NEJM200103153441101

48. O'Sullivan CC, Bradbury I, Campbell C, Spielmann M, Perez EA, Joensuu H, et al. Efficacy of Adjuvant Trastuzumab for Patients With Human Epidermal Growth Factor Receptor 2-Positive Early Breast Cancer and Tumors $\leq 2 \mathrm{~cm}$ : A Meta-Analysis of the Randomized Trastuzumab Trials. J Clin Oncol [Internet]. 2015 Aug 20;33(24):2600-8. Available from: https:// ascopubs.org/doi/10.1200/JCO.2015.60.8620

49. Perou CM, Sørlie T, Eisen MB, van de Rijn M, Jeffrey SS, Rees CA, et al. Molecular portraits of human breast tumours. Nature [Internet]. 2000 Aug;406(6797):747-52. Available from: http://www.nature.com/articles/35021093

50. Prat A, Pineda E, Adamo B, Galván P, Fernández A, Gaba L, et al. Clinical implications of the intrinsic molecular subtypes of breast cancer. The Breast [Internet]. 2015 Nov;24:S26-35. Available from: https://linkinghub.elsevier.com/retrieve/ pii/S0960977615001460

51. Vieira AF, Schmitt F. An Update on Breast Cancer Multigene Prognostic Tests-Emergent Clinical Biomarkers. Front Med [Internet]. 2018 Sep 4;5(SEP):248. Available from: https://www.frontiersin.org/article/10.3389/fmed.2018.00248/full

52. Cardoso F, van't Veer LJ, Bogaerts J, Slaets L, Viale G, Delaloge S, et al. 70-Gene Signature as an Aid to Treatment Decisions in Early-Stage Breast Cancer. N Engl J Med [Internet]. 2016 Aug 25;375(8):717-29. Available from: http://www. nejm.org/doi/10.1056/NEJMoa1602253

53. Sparano JA, Gray RJ, Makower DF, Pritchard KI, Albain KS, Hayes DF, et al. Adjuvant Chemotherapy Guided by a 21-Gene Expression Assay in Breast Cancer. N Engl J Med [Internet]. 2018 Jul 12;379(2):111-21. Available from: http://www.nejm. org/doi/10.1056/NEJMoa1804710

54. Győrffy B, Hatzis C, Sanft T, Hofstatter E, Aktas B, Pusztai L. Multigene prognostic tests in breast cancer: past, present, future. Breast Cancer Res [Internet]. 2015 Dec 27;17(1):11. Available from: http://breast-cancer-research.biomedcentral. com/articles/10.1186/s13058-015-0514-2

55. Zhao X, Rødland EA, Sørlie T, Vollan HKM, Russnes HG, Kristensen VN, et al. Systematic assessment of prognostic gene signatures for breast cancer shows distinct influence of time and ER status. BMC Cancer [Internet]. 2014 Dec 19;14(1):211. Available from: http://bmccancer.biomedcentral.com/articles/10.1186/1471-2407-14-211

56. Iwamoto T, Lee J-S, Bianchini G, Hubbard RE, Young E, Matsuoka J, et al. First generation prognostic gene signatures for breast cancer predict both survival and chemotherapy sensitivity and identify overlapping patient populations. Breast Cancer Res Treat [Internet]. 2011 Nov 11;130(1):155-64. Available from: http://link.springer.com/10.1007/s10549011-1706-9

57. Kelly CM, Bernard PS, Krishnamurthy S, Wang B, Ebbert MTW, Bastien RRL, et al. Agreement in Risk Prediction Between the 21-Gene Recurrence Score Assay (Onco type DX ${ }^{\circledR}$ ) and the PAM50 Breast Cancer Intrinsic ClassifierTM in Early-Stage Estrogen Receptor-Positive Breast Cancer. Oncologist [Internet]. 2012 Apr 14;17(4):492-8. Available from: https://onlinelibrary.wiley.com/doi/abs/10.1634/theoncologist.2012-0007

58. Prat A, Parker JS, Fan C, Cheang MCU, Miller LD, Bergh J, et al. Concordance among gene expression-based predictors for ER-positive breast cancer treated with adjuvant tamoxifen. Ann Oncol [Internet]. 2012 Nov;23(11):2866-73. Available from: https://linkinghub.elsevier.com/retrieve/pii/S0923753419375039

59. Goetz MP, Gradishar WJ, Anderson BO, Abraham J, Aft R, Allison KH, et al. Breast Cancer, Version 3.2018. J Natl Compr Cancer Netw [Internet]. 2019 Feb;17(2):118-26. Available from: https://inccn.org/view/journals/jnccn/17/2/article-p118.xml

60. Arnedos M, Gligorov J. St Gallen International Consensus Guidelines in early breast cancer: experts to prevent patients' overtreatment and breaking the bank? Ann Oncol [Internet]. 2019 Oct;30(10):1533-5. Available from: https://linkinghub.elsevier.com/retrieve/pii/S0923753419609853

61. Andre F, Ismaila N, Henry NL, Somerfield MR, Bast RC, Barlow W, et al. Use of Biomarkers to Guide Decisions on Adjuvant Systemic Therapy for Women With Early-Stage Invasive Breast Cancer: ASCO Clinical Practice Guideline Update-Integration of Results From TAILORx. J Clin Oncol [Internet]. 2019 Aug 1;37(22):1956-64. Available from: https://ascopubs.org/ doi/10.1200/JCO.19.00945 
62. Henry NL, Somerfield MR, Abramson VG, Ismaila N, Allison KH, Anders CK, et al. Role of Patient and Disease Factors in Adjuvant Systemic Therapy Decision Making for Early-Stage, Operable Breast Cancer: Update of the ASCO Endorsement of the Cancer Care Ontario Guideline. J Clin Oncol [Internet]. 2019 Aug 1;37(22):1965-77. Available from: https://ascopubs.org/doi/10.1200/JCO.19.00948

63. Weis J. Support groups for cancer patients. Support Care Cancer [Internet]. 2003 Dec 1;11(12):763-8. Available from: http://link.springer.com/10.1007/s00520-003-0536-7

64. Constance ES, Moravek MB, Jeruss JS. Strategies to Maintain Fertility in Young Breast Cancer Patients. In: Cancer Treatment and Research [Internet]. Springer International Publishing; 2018. p. 1-13. Available from: http://link.springer. com/10.1007/978-3-319-70197-4 1

65. Islam T, Dahlui M, Majid H, Nahar A, Mohd Taib N, Su T. Factors associated with return to work of breast cancer survivors: a systematic review. BMC Public Health [Internet]. 2014 Nov;14(Suppl 3):S8. Available from: http://bmcpublichealth. biomedcentral.com/articles/10.1186/1471-2458-14-S3-S8

66. Hauglann B, Benth JŠ, Fosså SD, Dahl AA. A cohort study of permanently reduced work ability in breast cancer patients. J Cancer Surviv [Internet]. 2012 Sep 29;6(3):345-56. Available from: http://link.springer.com/10.1007/s11764-012$\underline{0215-0}$

67. Narod SA, Iqbal J, Miller AB. Why have breast cancer mortality rates declined? J Cancer Policy [Internet]. 2015 Sep;5:817. Available from: https://linkinghub.elsevier.com/retrieve/pii/S2213538315000065

68. Sledge GW, Mamounas EP, Hortobagyi GN, Burstein HJ, Goodwin PJ, Wolff AC. Past, Present, and Future Challenges in Breast Cancer Treatment. J Clin Oncol [Internet]. 2014 Jul 1;32(19):1979-86. Available from: http://ascopubs.org/ doi/10.1200/JCO.2014.55.4139

69. Fisher B, Costantino JP, Wickerham DL, Redmond CK, Kavanah M, Cronin WM, et al. Tamoxifen for Prevention of Breast Cancer: Report of the National Surgical Adjuvant Breast and Bowel Project P-1 Study. JNCl J Natl Cancer Inst [Internet]. 1998 Sep 16;90(18):1371-88. Available from: https://academic.oup.com/inci/article/90/18/1371/897928

70. Vogel VG, Costantino JP, Wickerham DL, Cronin WM, Cecchini RS, Atkins JN, et al. Update of the National Surgical Adjuvant Breast and Bowel Project Study of Tamoxifen and Raloxifene (STAR) P-2 Trial: Preventing Breast Cancer. Cancer Prev Res [Internet]. 2010 Jun 1;3(6):696-706. Available from: http://cancerpreventionresearch.aacrjournals.org/cgi/ doi/10.1158/1940-6207.CAPR-10-0076

71. Goss PE, Ingle JN, Alés-Martínez JE, Cheung AM, Chlebowski RT, Wactawski-Wende J, et al. Exemestane for Breast-Cancer Prevention in Postmenopausal Women. N Engl J Med [Internet]. 2011 Jun 23;364(25):2381-91. Available from: http:// www.nejm.org/doi/10.1056/NEJMoa1103507

72. Cuzick J, Sestak I, Forbes JF, Dowsett M, Cawthorn S, Mansel RE, et al. Use of anastrozole for breast cancer prevention (IBIS-II): long-term results of a randomised controlled trial. Lancet [Internet]. 2020 Jan;395(10218):117-22. Available from: https://linkinghub.elsevier.com/retrieve/pii/S0140673619329551

73. Seely JM, Alhassan T. Screening for breast cancer in 2018 - what should we be doing today? Curr Oncol [Internet]. 2018 Jun 14;25(Suppl 1):115. Available from: http://current-oncology.com/index.php/oncology/article/view/3770

74. Siravegna G, Marsoni S, Siena S, Bardelli A. Integrating liquid biopsies into the management of cancer. Nat Rev Clin Oncol [Internet]. 2017 Sep 2;14(9):531-48. Available from: http://www.nature.com/articles/nrclinonc.2017.14

75. Hannafon BN, Trigoso YD, Calloway CL, Zhao YD, Lum DH, Welm AL, et al. Plasma exosome microRNAs are indicative of breast cancer. Breast Cancer Res [Internet]. 2016 Dec 8;18(1):90. Available from: https://breast-cancer-research.biomedcentral.com/articles/10.1186/s13058-016-0753-x

76. Rack B, Schindlbeck C, Jückstock J, Andergassen U, Hepp P, Zwingers T, et al. Circulating Tumor Cells Predict Survival in Early Average-to-High Risk Breast Cancer Patients. JNCI J Natl Cancer Inst [Internet]. 2014 May;106(5). Available from: https://academic.oup.com/inci/article-lookup/doi/10.1093/inci/dju066

77. Lin NU, Borges V, Anders C, Murthy RK, Paplomata E, Hamilton E, et al. Intracranial Efficacy and Survival With Tucatinib Plus Trastuzumab and Capecitabine for Previously Treated HER2-Positive Breast Cancer With Brain Metastases in the HER2CLIMB Trial. J Clin Oncol [Internet]. 2020 Aug 10;38(23):2610-9. Available from: https://ascopubs.org/doi/10.1200/ $\underline{\mathrm{JCO} .20 .00775}$

78. Bedognetti D, Hendrickx W, Marincola FM, Miller LD. Prognostic and predictive immune gene signatures in breast cancer. Curr Opin Oncol [Internet]. 2015 Nov;27(6):433-44. Available from: http://journals.Iww.com/00001622201511000-00003

79. Kwon MJ. Emerging immune gene signatures as prognostic or predictive biomarkers in breast cancer. Arch Pharm Res [Internet]. 2019 Nov 9;42(11):947-61. Available from: http://link.springer.com/10.1007/s12272-019-01189-y 